\section{LUPUS SCIENCE\& MEDICINE}

\title{
Cross-sectional study of the effects of self-efficacy on fatigue and pain interference in black women with systemic lupus erythematosus: the role of depression, age and education
}

Cristina Drenkard (D) , ${ }^{1,2}$ Kirk Easley, ${ }^{3}$ Gaobin Bao, ${ }^{1}$ Charmayne Dunlop-Thomas, ${ }^{1}$ S Sam Lim (i) , ${ }^{1,2}$ Teresa Brady ${ }^{4}$

To cite: Drenkard C, Easley K, Bao G, et al. Cross-sectional study of the effects of selfefficacy on fatigue and pain interference in black women with systemic lupus erythematosus: the role of depression, age and education. Lupus Science \& Medicine 2022;9:e000566. doi:10.1136/ lupus-2021-000566

- Additional supplemental material is published online only. To view, please visit the journal online (http://dx.doi.org/10. 1136/lupus-2021-000566).

Received 25 August 2021 Accepted 6 January 2022

Check for updates

(C) Author(s) (or their employer(s)) 2022. Re-use permitted under CC BY-NC. No commercial re-use. See rights and permissions. Published by BMJ.

For numbered affiliations see end of article.

Correspondence to Dr Cristina Drenkard; CDRENKA@emory.edu

\section{ABSTRACT}

Objective While fatigue and pain are pervasive symptoms in SLE, self-efficacy can mitigate their intensity and impact on patients' daily activity. We examined the relationships of these domains and their interactions with demographics and depression in black women with SLE.

Methods This is a cross-sectional analysis of data collected among 699 black women with SLE. We used validated, self-reported measures of fatigue, pain interference, symptom self-efficacy, treatment selfefficacy and depression. Linear regression analyses were conducted to examine the relationships between each outcome (fatigue and pain interference) and each predictor (symptom self-efficacy and treatment self-efficacy), and the interaction of demographics and depression.

Results We found inverse associations between fatigue and each of symptom self-efficacy (slope -0.556 , $p<0.001$ ) and treatment self-efficacy (slope -0.282 , $p<0.001$ ), as well as between pain interference and each of symptom self-efficacy (slope $-0.394, p<0.001$ ) and treatment self-efficacy (slope $-0.152, p<0.001$ ). After adjusting for confounders, symptom self-efficacy remained significantly associated with each outcome (adjusted slope $-0.241(p<0.001)$ and $-0.103(p=0.008)$ for fatigue and pain, respectively). The amount of decrease in fatigue and pain interference differed by depression severity $(p<0.05$ for the interaction of symptom self-efficacy and depression). The difference in fatigue by depression widened as symptom self-efficacy increased; the adjusted fatigue scores for moderate/severe depression compared with no depression were 6.8 and 8.7 points higher at mean and high symptom self-efficacy, respectively $(p<0.001)$. Age and education significantly changed the relationship between outcomes and self-efficacy. Conclusions Symptom self-efficacy and treatment self-efficacy were inversely related to fatigue and pain interference in black women with SLE. Depression disproportionately increased the intensity of these outcomes. While older women with low symptom self-efficacy reported disproportionately higher pain interference, those with higher education and mean or high levels of symptom self-efficacy reported lower pain interference. These findings may help predict who might benefit most from self-efficacy-enhancing interventions.

\section{Key messages}

What is already known about this subject?

- Self-efficacy can mitigate fatigue and the impact of pain on daily activities in individuals with chronic conditions; however, individual characteristics may modify the effect of self-efficacy on these outcomes.

- Despite the high prevalence of fatigue and pain in SLE, little is known about the impact of self-efficacy on these symptoms among under-represented populations with this condition.

What does this study add?

- We underscored that self-efficacy (to manage symptoms and to manage medications and treatments) was inversely related to fatigue and pain interference in black women with SLE.

- Some of these associations were modified by age, educational attainment and depressive symptoms in these women.

How might this impact on clinical practice or future developments?

- Self-efficacy-building interventions can potentially alleviate fatigue and pain, improving the quality of life of black women with SLE; however, lower beneficial effects are expected in women with depression and those who are older or achieved less education.

- Depression, a highly prevalent and often underdiagnosed comorbidity in SLE, disproportionately increased the intensity of fatigue and pain interference, particularly among women with average and high self-efficacy.

- Improving depression screening and management is critical to control these pervasive symptoms and improve the quality of life of the SLE population.

\section{INTRODUCTION}

SLE is an autoimmune chronic disease that disproportionately strikes young women and black individuals. Pain and fatigue are two of the most pervasive and distressing symptoms 
reported by people living with SLE. ${ }^{1-3}$ Not only do these symptoms occur in patients with active lupus, they are also reported by patients who have, otherwise, the disease under control. ${ }^{4}$ Pain and fatigue are independent factors associated with unemployment and disability, ${ }^{5}$ and patients with SLE often report these symptoms to be the most challenging to self-manage and the most important treatment goals. ${ }^{6}$ However, pain and fatigue remain largely unaddressed despite treatment advances. ${ }^{78}$

Multiple factors have been found to cause, exacerbate or mitigate pain and fatigue in patients with SLE ${ }^{9-13}$ While comorbidities and psychological distress play important roles in the occurrence of these symptoms, ${ }^{14-16}$ there is also variation by sociodemographic factors. ${ }^{17}$ Racial disparities have been described in pain outcomes, with greater pain severity and pain-related physical and psychosocial disability among black compared with white individuals. ${ }^{18}$ Moreover, depression, a comorbidity present in one-third of black individuals with SLE, can cause or exacerbate chronic pain and fatigue. ${ }^{19}{ }^{20}$ We reported that disease activity, organ damage, and psychosocial and demographic factors accounted for pain outcomes in a predominantly black, population-based SLE cohort in Southeastern USA. ${ }^{21}$ Moreover, fatigue significantly reduced work productivity in these patients, potentially threatening employment sustainability. ${ }^{22}$ Thus, these symptoms may have a substantial individual and societal toll, with escalating negative effects among black individuals, women and other high-risk groups with SLE.

Self-efficacy is 'the belief in one's capabilities to organize and execute the courses of action required to manage prospective situations'. ${ }^{23}$ A meta-analysis highlighted a protective role of self-efficacy against chronic pain, ${ }^{24}$ and self-management programmes built on selfefficacy have been shown to mitigate fatigue and pain. ${ }^{25} 26$ In patients with SLE, higher levels of self-efficacy for pain control correlated with lower levels of pain, stiffness, fatigue and negative mood. ${ }^{27} \mathrm{~A}$ large body of research has described an inverse correlation between depression and self-efficacy, with reciprocal influences among mood disorders, self-efficacy and self-management tasks. Some findings indicate that people with mood disorders may have lower self-efficacy, ${ }^{28-30}$ whereas others suggest that high self-efficacy may protect against depression. ${ }^{31}$ Remarkably, people with depression may benefit more from self-efficacy-enhancing interventions, such as the Chronic Disease Self-Management Program (CDSMP) ${ }^{32}{ }^{33}$ Findings also suggest that self-efficacy and people's response to self-efficacy-building interventions may differ by sociodemographic characteristics. A recent study underlined that racial minorities with diabetes have lower self-efficacy than white individuals, and that race moderated the relation between self-care and psychological distress among older patients. ${ }^{34}$ While the interaction effect of age has shown mixed effects, ${ }^{35-38}$ people with higher educational attainment have been found to have higher levels of self-efficacy and may benefit more from self-efficacy-building programmes. ${ }^{38} 39$
Little is known about self-efficacy in under-represented populations with SLE. In this paper, we examined the correlation between self-efficacy and both pain interference and fatigue in a cohort of black women with SLE who participated in a CDSMP effectiveness study. Moreover, because mood disorders and demographic characteristics can potentially interact with self-efficacy, we aimed to determine whether depression, age and education may alter those associations in this high-risk population.

\section{METHODS}

\section{Study population}

We examined baseline data collected for the Women Empowered to Live with Lupus (WELL) study, a trial conducted to determine the effectiveness of the CDSMP among black women with SLE. ${ }^{40}$ Briefly, WELL participants were recruited from Georgians Organized Against Lupus (GOAL), a population-based cohort of individuals with SLE largely derived from the Georgia Lupus Registry. ${ }^{41}$ GOAL encompasses over 1000 participants with a validated diagnosis of SLE, of whom nearly $80 \%$ are black. The cohort includes participants of broad disease severity spectrum and all socioeconomic levels, who have been surveyed regularly since 2011 using patient-reported instruments.

The WELL study is a two-group longitudinal cohort of black women with SLE nested within the GOAL cohort that aims to compare outcomes of women enrolled in the CDSMP ( $n=168$, randomly selected from GOAL) with those not exposed to the intervention ( $\mathrm{n}=531$, nonselected from GOAL). For this study, we conducted a cross-sectional analysis of baseline data, including the entire sample ( $\mathrm{n}=699$ black women; (online supplemental figure 1). All participants signed the informed consent.

\section{Patient and public involvement}

We have convened a diverse group of GOAL participants into the Lupus Patient Advisory Research Council (L-PARC). L-PARC members meet at least once a year with researchers to provide feedback on study measures and advice on recruitment, retention and dissemination of findings.

\section{Measures}

We used the Patient-Reported Outcomes Measurement Information System (PROMIS) adult short forms (SF) to measure fatigue, pain interference, self-efficacy to manage symptoms, self-efficacy to manage medications and treatments, and depression. We used PROMIS measures because they have been validated in patients with a variety of chronic conditions, including SLE, and are recommended over other legacy measures due to their flexibility and precision. ${ }^{42}{ }^{43}$ Each of these tools uses a five-item Likert scale scored from 1 to 5 ; raw scores were individually calculated and converted to T-scores by the Health Measures Scoring Service. ${ }^{44}$ The T-score rescales the raw score into a standardised score with a mean of 50 and an SD of 10. To avoid missing data, we conducted 
monthly data quality checks and called participants to answer missing questions.

\section{Outcomes}

Fatigue was measured using the PROMIS Fatigue SF8a. This eight-item questionnaire measures both the experience of fatigue and the interference of fatigue on daily activities over the past week. Examples of items are 'How run-down did you feel on average' and 'How often did you have to push yourself to get things done because of your fatigue'. Response options range from $1=$ not at all to $5=$ verymuch. A higher PROMIS T-score represents more fatigue and fatigue interference. Pain interference was measured using the PROMIS Pain Interference SF8a. This eight-item questionnaire quantifies the impact of pain (from $1=$ not at all to $5=$ very much) on daily activities, working around the house, participation in social activities and household chores in the past 7 days. A higher PROMIS T-score represents higher pain interference on daily activities. Both fatigue and pain interference scales have demonstrated good reliability and validity in diverse populations. ${ }^{45-47}$

\section{Predictors}

Self-efficacy to manage symptoms (symptom self-efficacy) was measured with the PROMIS Self-Efficacy for Managing Symptoms SF4a. This four-item scale quantifies the level of current confidence (from $1=$ not confident at all to $5=$ very confident) a person with a chronic condition has in managing symptoms and keeping symptoms from interfering with social relationships. Self-efficacy to manage medications and treatments (treatment self-efficacy) was measured with the PROMIS Self-Efficacy for Managing Medications and Treatments SF8a. This eight-item tool quantifies the level of current confidence (from $1=$ not confident at all to $5=$ very confident) a person with a chronic condition has in taking and managing medication and other treatments in challenging situations (eg, travelling, running out of medication, occurrence of side effects). Both measures are derived from the five-domain PROMIS Self-Efficacy for Managing Chronic Conditions item banks, demonstrating good reliability and validity. ${ }^{48}$

\section{Covariates}

Depression was measured using PROMIS Depression SF8a, an eight-item scale to quantify the frequency (from $1=$ never to $5=$ always) of negative mood (eg, sadness, guilt), views of self (eg, self-criticism, worthlessness), social cognition (eg, loneliness), and decreased positive affect and engagement (eg, loss of interest) in the past 7 days. The scale has been validated in individuals with a variety of chronic conditions and was adopted by the Diagnostic and Statistical Manual of Mental Disorders (Fifth Edition). ${ }^{49}{ }^{50}$ PROMIS Depression has shown greater reliability and scores more closely approximating a normal distribution than two traditional legacy depression measures: the Patient Health Questionnaire 9 (PHQ-9) and the Center for Epidemiologic Studies Depression Scale
(CES-D) . It also showed strong convergent validity with the CES-D and the PHQ-9. ${ }^{51}$ To examine the severity of depression in this sample, T-scores $<52.5$ were categorised as none, 52.5 to $<60$ as mild, and $\geq 60$ as moderate/severe depression. These cut-offs correspond to those used with the analogous PHQ-9 scores. ${ }^{52} 53$ Age was calculated at baseline and categorised in three groups (18-34, 35-54, 55 or older). Educational attainment was self-reported and grouped into high school or below, some college, and bachelor's degree or above.

\section{Confounders}

Insurance (federal (Medicare and/or Medicaid), private, no insurance) and work status (employed, out of the labour force (comprising retirees, home makers and students), unemployed or disabled) and disease duration (years) were measured with ad-hoc questions. Disease activity and organ damage accrual were measured using validated self-reported instruments: the Systemic Lupus Activity Questionnaire (SLAQ; score range $=0-47)^{54}$ and the Self-Administered Brief Index of Lupus Damage (SABILD; score range $=0-30) .{ }^{55}$

\section{Statistical analysis}

Simple and multivariate linear regression was used to examine the cross-sectional relationship between each outcome (fatigue and pain interference) and each predictor (symptom self-efficacy and treatment self-efficacy). The linear slope for each outcome was compared with zero. Because previous data suggest that younger individuals and those with depression may be more responsive to the CDSMP, and those who achieve lower educational attainment may have lower selfefficacy, ${ }^{35-37} 3956$ we also examined whether these factors interact with each measure of self-efficacy to affect the relationship between self-efficacy and each outcome. We assumed that each outcome could be expressed as a linear function of self-efficacy with possible different intercepts and slopes for each level of depression (none, mild, moderate/severe). Predictors included self-efficacy, depression and the interaction between self-efficacy and depression. Thus, the self-efficacy-adjusted outcome mean was calculated by evaluating the regression equation for each depression group at the mean (and at low (T-score 35) and high (T-score 55)) self-efficacy. These analyses were adjusted for the other two covariates of interest (age and education) and confounders (insurance, work status, disease duration, disease activity and organ damage accrual). A similar approach was applied when we examined the interaction between each measure of self-efficacy and either age or education. To ensure independence between fatigue and the confounder effect of disease activity (measured with SLAQ), the adjusted means and slopes of fatigue were estimated by omitting the fatigue response in SLAQ. Model fit was assessed using $R^{2}$ and mean square error statistics. Examination of multicollinearity using variance inflation factors did not suggest large correlations among pairs of predictor variables in 
Table 1 Univariate and multiple linear regression of fatigue and pain interference on self-efficacy

\begin{tabular}{|c|c|c|c|c|c|c|c|c|}
\hline \multirow[b]{2}{*}{ Factor } & \multicolumn{4}{|l|}{ Fatigue } & \multicolumn{4}{|c|}{ Pain interference } \\
\hline & $\begin{array}{l}\text { Slope* }^{*} \pm \text { SE) } \\
\text { (per 1-point } \uparrow)\end{array}$ & $\begin{array}{l}\text { Slope } \\
\text { (per 5-point } \uparrow \text { ) }\end{array}$ & P value & MSE & $\begin{array}{l}\text { Slope }^{\star}( \pm S E) \\
\text { (per 1-point } \uparrow)\end{array}$ & $\begin{array}{l}\text { Slope } \\
\text { (per 5-point } \uparrow \text { ) }\end{array}$ & P value & MSE \\
\hline \multicolumn{9}{|l|}{ Univariate } \\
\hline $\begin{array}{l}\text { Symptom self- } \\
\text { efficacy }\end{array}$ & $-0.556 \pm 0.044$ & -2.781 & $<0.001$ & 97.4 & $-0.394 \pm 0.042$ & -1.971 & $<0.001$ & 87.4 \\
\hline $\begin{array}{l}\text { Treatment self- } \\
\text { efficacy }\end{array}$ & $-0.282 \pm 0.044$ & -1.411 & $<0.001$ & 113.4 & $-0.152 \pm 0.041$ & -0.760 & $<0.001$ & 96.7 \\
\hline \multicolumn{9}{|l|}{ Multiple† } \\
\hline $\begin{array}{l}\text { Symptom self- } \\
\text { efficacy }\end{array}$ & $-0.241 \pm 0.043$ & -1.204 & $<0.001$ & 66.9 & $-0.103 \pm 0.040$ & -0.537 & 0.008 & 59.9 \\
\hline $\begin{array}{l}\text { Treatment self- } \\
\text { efficacy }\end{array}$ & $-0.072 \pm 0.038$ & -0.360 & 0.055 & 70.0 & $0.025 \pm 0.035$ & 0.127 & 0.47 & 60.6 \\
\hline
\end{tabular}

*Indicates b regression coefficient.

†Adjusted for age, disease duration, education, work status, insurance, depression, disease activity (SLAQ) and organ damage (SA-BILD). MSE, mean square error; SA-BILD, Self-Administered Brief Index of Lupus Damage; SLAQ, Systemic Lupus Activity Questionnaire.

the multiple linear regression models. Statistical analyses were conducted using SAS V.9.4 software.

\section{RESULTS}

\section{Study population description}

The mean age of the 699 black women who participated in the study was 47.9 years (SD 13.7), with $143(20.5 \%)$ aged 18-34, $329(47.1 \%)$ aged 35-54, and $227(32.5 \%)$ aged 55 or older, (online supplemental table 1). Of the participants, 261 (37.4\%) reported high school or below, $226(32.4 \%)$ some college, and 211 (30.2\%) bachelor's degree or above. Of the participants, 302 (43.6\%) were unemployed or disabled, $249(35.9 \%)$ worked full-time or part-time, and the remaining $142(20.5 \%)$ were out of the labour force. The mean SLE duration was 15.6 (SD 10.3) years, the mean disease activity 15.1 (SD 8.7) and the mean organ damage 2.6 (SD 2.5). Nearly half of the sample reported some level of depression, with $21.6 \%$ in the range of moderate/severe. The mean T-scores were 57.8 (SD 11.0) for fatigue, 58.0 (SD 9.9) for pain interference, 48.1 (SD 8.5) for symptom self-efficacy and 46.1 (SD 9.2) for treatment self-efficacy.

\section{Univariate and multiple regression}

The univariate analysis rendered a significant inverse association between fatigue and each self-efficacy domain (table 1). Fatigue declined by nearly 2.8 points per 5 -point increase in symptom self-efficacy (slope $=-0.556$, $\mathrm{p}<0.001)$ and by 1.4 points per 5 -point increase in treatment self-efficacy ( lope $=-0.282, \mathrm{p}<0.001)$. The univariate regressions of pain interference on each self-efficacy measure also showed significant inverse associations. Pain interference declined by nearly 2.0 points per 5-point increase in symptom self-efficacy ( and by nearly 0.8 points per 5 -point increase in treatment self-efficacy $\quad$ (slope $=-0.152, \mathrm{p}<0.001)$. After adjusting for confounders, symptom self-efficacy remained significantly associated with each outcome (adjusted slope
$-0.241 \quad(\mathrm{p}<0.001)$ and $-0.103(\mathrm{p}=0.008)$ for fatigue and pain, respectively; table 1 ).

\section{Statistical interactions}

We explored separately fatigue-symptom self-efficacy and fatigue-treatment self-efficacy slopes for each level of depression, age and educational attainment (figure 1). A significant interaction $(p=0.03)$ was found between symptom self-efficacy and depression (figure 1A). Symptom self-efficacy did not interact significantly with age $(p=0.08$; figure $1 B)$, but showed a significant interaction with education $(\mathrm{p}=0.009$; figure $1 \mathrm{C})$. Similarly, we found a significant interaction between treatment selfefficacy and depression on fatigue $(p=0.006$; figure 1D). The fatigue-treatment self-efficacy slope did not change significantly with age $(p=0.1$; figure $1 E)$, whereas educational attainment showed a significant interaction $(\mathrm{p}=0.03$; figure $1 \mathrm{~F})$.

Figure 2 illustrates that depression did not change the slope of pain interference regressed on symptom selfefficacy ( $p=0.1$; figure $2 \mathrm{~A})$; however, a significant interaction was identified between symptom self-efficacy and age $(p=0.03$; figure $2 B)$. Education showed a statistically significant interaction ( $p=0.0009$; figure 2C), suggesting that at high levels of symptom self-efficacy women who attained bachelor's degree or above had a significantly lower amount of pain interference. The regression of pain interference on treatment self-efficacy was modified by depression $(p=0.03$; figure $2 \mathrm{D})$ but not by age $(\mathrm{p}=0.2$; figure $2 \mathrm{E}$ ) or education ( $\mathrm{p}=0.10$; figure $2 \mathrm{~F}$ ).

Combined effect of self-efficacy and either depression, age or education on the adjusted mean of the study outcomes/ multiple linear regression analysis

We examined whether each variable of interest (depression, age and education) would have a joint effect on the adjusted mean of each study outcome at three levels of 

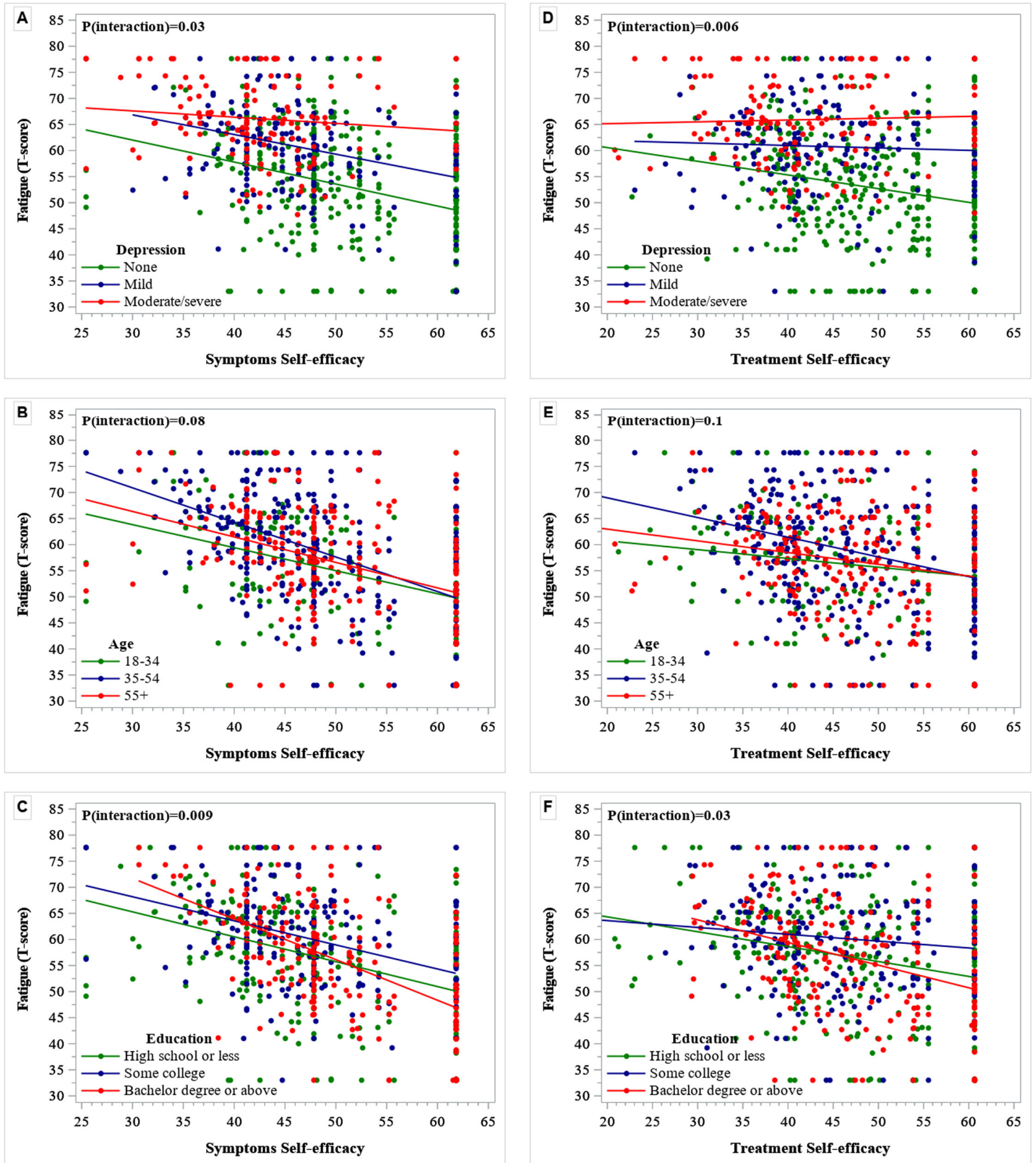

Figure 1 Regression of fatigue on symptom self-efficacy (A, B, and C) and treatment self-efficacy (D, E, and F) by depression ( $A$ and $D)$, age $(B$ and $E)$, and educational attainment ( $C$ and $F$ ) categories. Fatigue and each self-efficacy measure are expressed as T-scores, with higher scores indicating more of the domain being measured. A p-value $<0.05$ indicates a significant interaction of a given factor (depression, age, or education) with a given self-efficacy (to manage symptoms or to manage treatment) on the relationship between the corresponding self-efficacy measure and fatigue.

each self-efficacy measure: mean T-score, low self-efficacy (T-score 35) and high self-efficacy (T-score 55).

\section{Fatigue}

Symptom self-efficacy and depression showed a significant interaction summarised as the adjusted mean of fatigue ( $\mathrm{p}=0.04$; table 2 ). At low symptom self-efficacy, the adjusted mean of fatigue increased progressively from women without depression to those with mild depression and those with moderate/severe depression. However, the mean difference was significantly higher only in women with moderate/severe depression compared with those without depression (mean difference 3.3, $\mathrm{p}=0.02$ ). At mean (T-score 48.1) and high (T-score 55) symptom self-efficacy, the adjusted means for fatigue were significantly higher for women with moderate/severe depression compared with those 

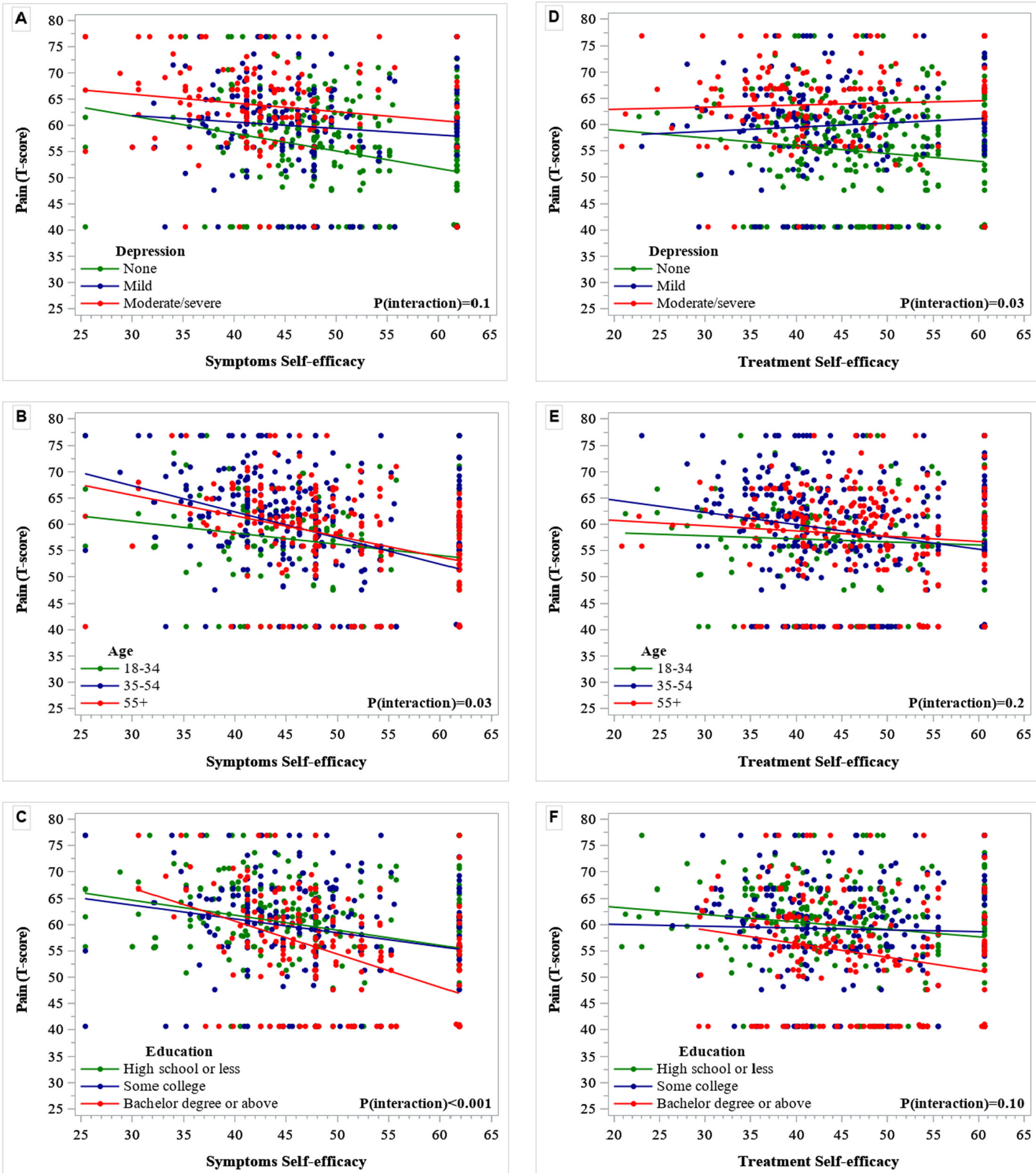

Figure 2 Regression of pain interference on symptom self-efficacy (A, B, and C) and treatment self-efficacy (D, E, and F) by depression ( $A$ and $D)$, age ( $B$ and $E$ ) and educational attainment ( $C$ and $F$ ) categories. Pain interference and each selfefficacy measure are expressed as T-scores, with higher scores indicating more of the domain being measured. A p-value $<0.05$ indicates a significant interaction of a given factor (depression, age, or education) with a given self-efficacy (to manage symptoms or to manage treatment) on the relationship between the corresponding self-efficacy measure and pain interference.

with mild or without depression. The highest mean difference was observed for women with moderate/ severe depression compared with those without depression (mean difference $6.8(\mathrm{p}<0.001)$ at mean and 8.7 $(\mathrm{p}<0.001)$ at high symptom self-efficacy).

The interactions between each self-efficacy measure and age did not have statistically significant effects on the slope of fatigue (online supplemental table 2). However, we found a significant interaction $(p=0.05)$ between symptom self-efficacy and education (table 2). At low symptom self-efficacy, the only significant difference was for women with bachelor's degree or above, who had a 4.4-point higher adjusted mean of fatigue, compared with women with high school or below $(p=0.003)$. At mean symptom self-efficacy, those with intermediate and highest education had significantly higher adjusted 
Table 2 Multiple linear regression analysis: combined effect of self-efficacy and either depression, age or educational attainment on the adjusted mean of fatigue

Self-efficacy to manage symptoms by depression ( $p$ value for the interaction=0.04)

\begin{tabular}{|c|c|c|c|c|c|}
\hline $\begin{array}{l}\text { Symptom SE level } \\
\text { (T-score) }\end{array}$ & $\begin{array}{l}\text { Depression severity } \\
\text { category }\end{array}$ & $\begin{array}{l}\text { Adjusted mean* } \\
(95 \% \text { Cl) }\end{array}$ & $\begin{array}{l}\text { Depression } \\
\text { severity } \\
\text { comparison }\end{array}$ & $\begin{array}{l}\text { Mean difference } \\
(95 \% \mathrm{Cl})\end{array}$ & $P$ value \\
\hline \multirow{3}{*}{$\begin{array}{l}\text { Low Symptom SE } \\
\text { (T-score }=35)\end{array}$} & 1. None & 59.8 (57.8 to 61.9 ) & 2 vs 1 & 2.9 (-0.1 to 6.0$)$ & 0.06 \\
\hline & 2. Mild & 62.8 (60.4 to 65.1$)$ & 3 vs $1 \S$ & 3.3 (0.5 to 6.2$)$ & 0.02 \\
\hline & 3. Moderate/severe & 63.2 (61.0 to 65.3 ) & 3 vs 2 & 0.4 (-2.6 to 3.4$)$ & 0.8 \\
\hline \multirow{3}{*}{$\begin{array}{l}\text { Mean Symptom SE } \\
(T-s c o r e=48.1)\end{array}$} & 1. No & 55.5 (54.4 to 56.6$)$ & 2 vs $1 \S$ & 3.4 (1.8 to 5.0$)$ & $<0.001$ \\
\hline & 2. Mild & 58.9 (57.6 to 60.3$)$ & 3 vs $1 \S$ & 6.8 (4.7 to 8.9$)$ & $<0.001$ \\
\hline & 3. Moderate/severe & 62.3 (60.5 to 64.2$)$ & 3 vs $2 \S$ & 3.4 (1.3 to 5.6$)$ & 0.002 \\
\hline \multirow{3}{*}{$\begin{array}{l}\text { High Symptom SE } \\
\text { (T-score }=55)\end{array}$} & 1. None & 53.2 (52.1 to 54.4$)$ & 2 vs $1 \S$ & 3.6 (1.5 to 5.8 ) & 0.001 \\
\hline & 2. Mild & 56.9 (54.9 to 58.9$)$ & 3 vs $1 \S$ & 8.7 (5.8 to 11.5$)$ & $<0.001$ \\
\hline & 3. Moderate/severe & 61.9 (59.2 to 64.6$)$ & 3 vs $2 \S$ & 5.0 (1.8 to 8.3 ) & 0.003 \\
\hline
\end{tabular}

Self-efficacy to manage symptoms by education ( $p$ value for the interaction $=0.05$ )

\begin{tabular}{|c|c|c|c|c|c|}
\hline $\begin{array}{l}\text { Symptom SE level } \\
\text { (T-score) }\end{array}$ & $\begin{array}{l}\text { Educational attainment } \\
\text { category }\end{array}$ & $\begin{array}{l}\text { Adjusted mean† } \\
(95 \% \mathrm{Cl})\end{array}$ & $\begin{array}{l}\text { Educational } \\
\text { attainment } \\
\text { comparison }\end{array}$ & Mean difference & $P$ value \\
\hline \multirow{3}{*}{$\begin{array}{l}\text { Low Symptom SE } \\
\text { (T-score=35) }\end{array}$} & 1. High school or below & 58.7 (56.9 to 60.6 ) & 2 vs 1 & $2.4(-0.2$ to 5.0$)$ & 0.07 \\
\hline & 2. Some college & 61.1 (59.0 to 63.2 ) & 3 vs $1 \S$ & 4.4 (1.5 to 7.4$)$ & 0.003 \\
\hline & 3. Bachelor's degree or above & 63.2 (60.6 to 65.7 ) & 3 vs 2 & 2.0 (-1.0 to 5.1$)$ & 0.2 \\
\hline \multirow{3}{*}{$\begin{array}{l}\text { Mean Symptom SE } \\
(T-\text { score }=48.1)\end{array}$} & 1. High school or below & 55.9 (54.7 to 57.2$)$ & 2 vs $1 \S$ & $3.2(1.7$ to 4.7$)$ & $<0.001$ \\
\hline & 2. Some college & 59.2 (58.0 to 60.3$)$ & 3 vs $1 \S$ & $2.2(0.5$ to 3.8$)$ & 0.009 \\
\hline & 3. Bachelor's degree or above & 58.1 (56.8 to 59.4$)$ & 3 vs 2 & $-1.0(-2.6$ to 0.6$)$ & 0.2 \\
\hline \multirow{3}{*}{$\begin{array}{l}\text { High Symptom SE } \\
\text { (T-score }=55)\end{array}$} & 1. High school or below & 54.5 (53.0 to 56.0 ) & 2 vs $1 \S$ & 3.6 (1.6 to 5.6 ) & $<0.001$ \\
\hline & 2. Some college & 58.1 (56.6 to 59.6$)$ & 3 vs 1 & 1.0 (-1.1 to 3.0$)$ & 0.4 \\
\hline & 3. Bachelor's degree or above & 55.4 (53.9 to 56.9 ) & 3 vs $2 \S$ & $-2.7(-4.7$ to -0.6$)$ & 0.01 \\
\hline
\end{tabular}

Self-efficacy to manage medications and treatments by depression ( $p$ value for the interaction $=0.009$ )

\begin{tabular}{|c|c|c|c|c|c|}
\hline $\begin{array}{l}\text { Treatment SE } \\
\text { level } \\
\text { (T-score) }\end{array}$ & Depression severity category & $\begin{array}{l}\text { Adjusted mean } ¥ \\
(95 \% \mathrm{Cl})\end{array}$ & $\begin{array}{l}\text { Depression } \\
\text { severity } \\
\text { comparison }\end{array}$ & Mean difference & $P$ value \\
\hline \multirow{3}{*}{$\begin{array}{l}\text { Low Treatment SE } \\
(\mathrm{T} \text {-score }=35)\end{array}$} & 1. None & 57.4 (55.6 to 59.1$)$ & 2 vs 1 & $2.2(-0.3$ to 4.8$)$ & 0.08 \\
\hline & 2. Mild & 59.6 (57.7 to 61.6$)$ & 3 vs $1 \S$ & 4.3 (1.7 to 6.9$)$ & 0.001 \\
\hline & 3. Moderate/severe & 61.6 (59.7 to 63.6$)$ & 3 vs 2 & 2.0 (-0.6 to 4.6$)$ & 0.1 \\
\hline \multirow{3}{*}{$\begin{array}{l}\text { Mean Treatment } \\
\text { SE } \\
\text { (T-score }=46.2)\end{array}$} & 1. None & 55.1 (53.9 to 56.2$)$ & 2 vs $1 \S$ & $4.1(2.5$ to 5.7$)$ & $<0.001$ \\
\hline & 2. Mild & 59.2 (57.8 to 60.5$)$ & 3 vs $1 \S$ & 7.3 (5.3 to 9.2$)$ & $<0.001$ \\
\hline & 3. Moderate/severe & $62.3(60.7$ to 64.0$)$ & 3 vs $2 \S$ & $3.2(1.2$ to 5.2$)$ & 0.002 \\
\hline \multirow{3}{*}{$\begin{array}{l}\text { High Treatment } \\
(\text { T-score }=55)\end{array}$} & 1. None & 53.2 (51.9 to 54.5$)$ & 2 vs $1 \S$ & 5.6 (3.3 to 7.9$)$ & $<0.001$ \\
\hline & 2. Mild & 58.8 (56.8 to 60.8$)$ & 3 vs $1 \S$ & 9.6 (7.0 to 12.3$)$ & $<0.001$ \\
\hline & 3. Moderate/severe & 62.8 (60.4 to 65.3$)$ & 3 vs $2 \S$ & 4.1 (1.1 to 7.1$)$ & 0.008 \\
\hline
\end{tabular}

*Adjusted for symptom SE, age, education, work status, insurance, disease duration, disease activity (SLAQ) and organ damage (SA-BILD). †Adjusted for symptom SE, depression, age, work status, insurance, disease duration, disease activity (SLAQ) and organ damage (SA-BILD). $\ddagger$ Adjusted for treatment SE, age, education, work status, insurance, disease duration, SLAQ and organ damage (SA-BILD).

$\S B$ Bold values indicate a statistically significant difference between the two groups.

SA-BILD, Self-Administered Brief Index of Lupus Damage; SE, self-efficacy; SLAQ, Systemic Lupus Activity Questionnaire.

means of fatigue than the high school or below group (mean difference $3.2 \quad(\mathrm{p}<0.001)$ and $2.2 \quad(\mathrm{p}=0.009)$, respectively). At high symptom self-efficacy, women who reported some college had significantly higher fatigue compared with high school or below (mean difference $3.6, \mathrm{p}<0.001$ ), whereas those with bachelor's degree or above reported less fatigue than those with some college (mean difference $-2.7, \mathrm{p}=0.01$ ). 
Treatment self-efficacy and depression also had a significant interaction $(p=0.009)$ on the adjusted mean of fatigue (table 2). At low treatment self-efficacy, women with moderate/severe depression had significantly higher fatigue than those without depression (mean difference 4.3, $\mathrm{p}=0.001$ ). At mean and high treatment self-efficacy, the adjusted mean T-scores for fatigue were significantly higher for women with moderate/severe depression compared with those without or with mild depression. Women with mild depression also had significantly higher adjusted mean fatigue T-scores than those without depression, at mean and high treatment self-efficacy. The largest differences were for moderate/severe depression compared with no depression. At mean treatment selfefficacy (T-score 46.2), women with moderate/severe depression had a 7.3-point higher adjusted mean T-score than those without depression $(p<0.001)$, and the mean difference was 9.6 points $(\mathrm{p}<0.001)$ at high treatment selfefficacy. The interactions between treatment self-efficacy and either age or education did not modify significantly the estimated adjusted slope of fatigue (online supplemental table 2).

\section{Pain interference}

Symptom self-efficacy and depression showed a significant interaction on pain interference, after adjusting for confounders $(\mathrm{p}=0.05$; table 3 and online supplemental table 3). At mean symptom self-efficacy, the adjusted mean for pain interference increased progressively from the group of women without depression to those with mild and moderate/severe depression. The only significant mean difference was, however, for moderate/severe depression compared with no depression (adjusted mean difference 2.0, $\mathrm{p}=0.04$ ). At high symptom self-efficacy, women with either mild or moderate/severe depression reported significantly greater pain interference compared with those without depression (adjusted mean difference $2.9(\mathrm{p}=0.006)$ and $2.8(\mathrm{p}=0.04)$ for mild vs no depression and moderate/severe vs no depression, respectively).

We observed a significant interaction between symptom self-efficacy and age $(\mathrm{p}=0.02)$. At low symptom self-efficacy, women aged 35-54 and those 55 or older had significantly higher pain interference than those in the youngest group (adjusted mean difference $5.0 \quad(\mathrm{p}<0.001)$ and $5.4(\mathrm{p}<0.001)$, respectively). At the mean symptom selfefficacy level (T-score=48.1), only middle-aged women had significantly higher adjusted mean for pain interference (mean difference 2.8, $\mathrm{p}<0.001$ ) compared with the youngest group. No significant differences were observed by age at high symptom self-efficacy.

Symptom self-efficacy and education showed a significant joint effect $(\mathrm{p}=0.04)$ on pain interference (table 3$)$. At the symptom self-efficacy mean T-score (48.1), women with the highest educational attainment reported a 1.8point lower adjusted pain interference T-score $(\mathrm{p}=0.02)$ than women who attended some college, and a 1.9-point lower T-score $(\mathrm{p}=0.02)$ than those who attained high school or below. The highest differences were, however, observed at high symptom self-efficacy (T-score $=55$ ), with $3.0(\mathrm{p}=0.002)$ and $3.4(\mathrm{p}<0.001)$ less points of adjusted T-scores for pain interference in women who reported the highest educational attainment compared with those who reported high school or below and some college, respectively. No significant differences were observed at low symptom self-efficacy (T-score 35) for adjusted T-scores of pain interference by educational attainment.

Neither depression, age nor education showed a significant interaction with treatment self-efficacy on pain interference, after adjusting for confounders (online supplemental table 3) .

\section{Sensitivity analyses}

Because SLAQ may capture non-inflammatory symptoms, we conducted sensitivity analyses to examine the combined effect of symptom self-efficacy (at mean T-score $=48.1$ ) and depression on both outcomes, after additional adjustments for steroid and/or immunosuppressive therapies as surrogates of active disease. Online supplemental tables 4 and 5 depict that the results remained similar.

\section{DISCUSSION}

Among black women with SLE, higher levels of self-efficacy to manage symptoms and treatments were inversely and independently associated with fatigue and pain interference. However, these associations were modified by age, educational attainment and depressive symptoms, and the effect of these interactions on women outcomes varied by the type and level of self-efficacy.

The inverse relationship between each measure of self-efficacy (to manage symptoms and to manage medications and treatments) and each outcome (pain interference and fatigue) was not unexpected. Yet, to our knowledge, these relationships have not been described in minorities with SLE. A recent study described an inverse association between organ damage and general self-efficacy in black but not in white individuals with SLE, despite similar levels of self-efficacy in both racial groups. ${ }^{57}$ Those findings suggest that black individuals may need to build greater self-efficacy to overcome the multiple challenges posed by the disease. Moreover, we found a greater effect of self-efficacy to manage symptoms on both outcomes. Thus, our findings point to the need for self-efficacy-building interventions, particularly those directed to manage symptoms, to improve the quality of life of black women with SLE.

Our study also underlined the potential moderation effect of depression on the association between selfefficacy and both fatigue and pain interference. At any given level of self-efficacy to either manage symptoms or treatments, patients with depression had a disproportionately higher intensity of fatigue than those without depression. The greatest differences were, however, for women with high levels of self-efficacy who also reported moderate/severe depression. These differences reached 
Table 3 Multiple linear regression analysis: combined effect of self-efficacy and either depression, age or educational attainment on the adjusted mean of pain interference

Self-efficacy to manage symptoms by depression ( $p$ value for the interaction $=0.05$ )

\begin{tabular}{|c|c|c|c|c|c|}
\hline $\begin{array}{l}\text { Symptom SE level } \\
\text { (T-score) }\end{array}$ & $\begin{array}{l}\text { Depression severity } \\
\text { category }\end{array}$ & $\begin{array}{l}\text { Adjusted mean* } \\
(95 \% \mathrm{Cl})\end{array}$ & $\begin{array}{l}\text { Depression } \\
\text { severity } \\
\text { comparison }\end{array}$ & Mean difference & $P$ value \\
\hline \multirow{3}{*}{$\begin{array}{l}\text { Low Symptom SE } \\
(\mathrm{T}-\mathrm{score}=35)\end{array}$} & 1. None & 59.5 (57.5 to 61.4$)$ & 2 vs 1 & $-1.7(-4.6$ to 1.1$)$ & 0.2 \\
\hline & 2. Mild & 57.7 (55.5 to 60.0 ) & 3 vs 1 & 0.5 (-2.2 to 3.2$)$ & 0.7 \\
\hline & 3. Moderate/severe & 59.9 (57.9 to 61.9$)$ & 3 vs 2 & $2.2(-0.6$ to 5.0$)$ & 0.1 \\
\hline $\begin{array}{l}\text { Mean Symptom SE } \\
(\text { T-score }=48.1)\end{array}$ & 3. Moderate/severe & 58.9 (57.1 to 60.6) & 3 vs 2 & $0.7(-1.3$ to 2.7$)$ & 0.5 \\
\hline \multirow{3}{*}{$\begin{array}{l}\text { High Symptom SE } \\
(\mathrm{T}-\mathrm{score}=55)\end{array}$} & 1. No & 55.5 (54.5 to 56.6$)$ & 2 vs $1 \S$ & 2.9 (0.8 to 4.9$)$ & 0.006 \\
\hline & 2. Mild & 58.4 (56.6 to 60.3$)$ & 3 vs $1 \S$ & $2.8(0.1$ to 5.5$)$ & 0.04 \\
\hline & 3. Moderate/severe & 58.3 (55.8 to 60.8$)$ & 3 vs 2 & $-0.1(-3.2$ to 3.0$)$ & 0.9 \\
\hline \multicolumn{6}{|c|}{ Self-efficacy to manage symptoms by age ( $p$ value for the interaction $=0.02$ ) } \\
\hline \multirow{3}{*}{$\begin{array}{l}\text { Low Symptom SE } \\
(\mathrm{T}-\mathrm{score}=35)\end{array}$} & 1. $18-34$ & 54.8 (52.4 to 57.2$)$ & 2 vs $1 \S$ & 5.0 (2.3 to 7.7$)$ & $<0.001$ \\
\hline & 2. $35-54$ & 59.8 (58.0 to 61.5$)$ & 3 vs $1 \S$ & $5.4(2.3$ to 8.6$)$ & $<0.001$ \\
\hline & 3. $55+$ & $60.2(58.0$ to 62.4$)$ & 3 vs 2 & $0.4(-2.2$ to 3.1$)$ & 0.8 \\
\hline \multirow{3}{*}{$\begin{array}{l}\text { Mean Symptom SE = } \\
(T-\text { score }=48.1)\end{array}$} & 1. $18-34$ & $55.6(54.1$ to 57.0$)$ & 2 vs $1 \S$ & $2.8(1.1$ to 4.4$)$ & 0.001 \\
\hline & 2. $35-54$ & $58.3(57.3$ to 59.3$)$ & 3 vs 1 & $2.0(-0.1$ to 4.0$)$ & 0.06 \\
\hline & 3. $55+$ & 57.5 (56.3 to 58.8$)$ & 3 vs 2 & $-0.8(-2.3$ to 0.7$)$ & 0.3 \\
\hline \multirow{3}{*}{$\begin{array}{l}\text { High Symptom SE } \\
\text { (T-score }=55)\end{array}$} & 1. $18-34$ & 56.0 (54.1 to 57.8) & 2 vs 1 & $1.6(-0.5$ to 3.7$)$ & 0.1 \\
\hline & 2. $35-54$ & 57.6 (56.3 to 58.9 ) & 3 vs 1 & $0.2(-2.3$ to 2.6$)$ & 0.9 \\
\hline & $3.55+$ & 56.1 (54.7 to 57.6) & 3 vs 2 & $-1.5(-3.3$ to 0.4$)$ & 0.1 \\
\hline
\end{tabular}

Self-efficacy to manage symptoms by education ( $p$ value for the interaction=0.04)

\begin{tabular}{|c|c|c|c|c|c|}
\hline $\begin{array}{l}\text { Symptom SE level } \\
\text { (T-score) }\end{array}$ & $\begin{array}{l}\text { Educational attainment } \\
\text { category }\end{array}$ & $\begin{array}{l}\text { Adjusted mean } \\
(95 \% \mathrm{Cl})\end{array}$ & $\begin{array}{l}\text { Educational } \\
\text { attainment } \\
\text { comparison }\end{array}$ & Mean difference & $P$ value \\
\hline \multirow{3}{*}{$\begin{array}{l}\text { Low Symptom SE } \\
\text { (T-score }=35)\end{array}$} & 1. High school or below & 59.2 (57.4 to 61.0$)$ & 2 vs 1 & $-1.0(-3.4$ to 1.5$)$ & 0.5 \\
\hline & 2. Some college & 58.3 (56.3 to 60.3 ) & 3 vs 1 & $0.4(-2.4$ to 3.2$)$ & 0.8 \\
\hline & 3. Bachelor's degree or above & 59.6 (57.2 to 62.0$)$ & 3 vs 2 & $1.3(-1.6$ to 4.2$)$ & 0.4 \\
\hline \multirow{3}{*}{$\begin{array}{l}\text { Mean Symptom SE } \\
\text { (T-score=48.1) }\end{array}$} & 1. High school or below & 58.1 (57.0 to 59.2$)$ & 2 vs 1 & $-0.1(-1.5$ to 1.4$)$ & 0.9 \\
\hline & 2. Some college & 58.0 (56.9 to 59.2$)$ & 3 vs $1 \S$ & $-1.9(-3.4$ to -0.3$)$ & 0.02 \\
\hline & 3. Bachelor's degree or above & 56.2 (55.1 to 57.4$)$ & 3 vs $2 \S$ & $-1.8(-3.3$ to -0.3$)$ & 0.02 \\
\hline \multirow{3}{*}{$\begin{array}{l}\text { High Symptom SE } \\
\text { (T-score=55) }\end{array}$} & 1. High school or below & 57.5 (56.1 to 58.9$)$ & 2 vs 1 & $0.4(-1.5$ to 2.3$)$ & 0.7 \\
\hline & 2. Some college & 57.9 (56.5 to 59.4$)$ & 3 vs $1 \S$ & $-3.0(-4.9$ to -1.1$)$ & 0.002 \\
\hline & 3. Bachelor's degree or above & 54.5 (53.1 to 55.9$)$ & 3 vs $2 \S$ & $-3.4(-5.4$ to -1.5$)$ & $<0.001$ \\
\hline
\end{tabular}

*Adjusted for symptom SE, age, education, work status, insurance disease duration, disease activity (SLAQ) and organ damage (SA-BILD). †Adjusted for symptom SE, depression, education, work status, insurance, disease duration, disease activity (SLAQ) and organ damage (SABILD).

‡Adjusted for symptom SE, depression, age, work status, insurance, disease duration, disease activity (SLAQ) and organ damage (SA-BILD). $\S B$ Bld values indicate a statistically significant difference between the two groups.

SA-BILD, Self-Administered Brief Index of Lupus Damage; SE, self-efficacy; SLAQ, Systemic Lupus Activity Questionnaire.

at least a half $\mathrm{SD}$ of fatigue in our sample, which is deemed to be the minimal difference that is clinically important in health-related quality of life scores. ${ }^{58}$ These results suggest that moderate/severe depression may overpower the beneficial effects of high levels of selfefficacy; therefore, interventions that tackle depression may be needed to achieve better control of fatigue even in people with high self-efficacy. Depression also modified 
the effect of symptom self-efficacy on pain interference, increasing the slope of the association, after adjusting for confounders. At high levels of symptom self-efficacy, women with depression (moderate/severe and mild) had disproportionately higher pain interference than those without depression, but the interaction was not significant among women who had low symptom self-efficacy. Depression is highly prevalent in minorities ${ }^{59}$; however, it is often undiagnosed and its negative impact on patient behaviours and disease outcomes is either unknown or underestimated by clinicians. Awareness of these interactions may help the clinical team to better address depression in black patients with SLE.

Age did not interact with self-efficacy on fatigue; however, it modified the effect of symptom self-efficacy on pain interference. Women 55 or older with low symptom self-efficacy reported disproportionately higher pain interference with daily activities compared with women younger than 35 years old. These findings provide a framework to explain previous data suggesting a better response of younger individuals to the CDSMP. ${ }^{35}$ Black women with SLE are younger at disease onset compared with their white counterparts, and black individuals have been reported to have lower pain tolerance and be more exposed to psychosocial factors that intensify negative pain experiences. ${ }^{18} 6061$ Consequently, our findings support the implementation of self-efficacy-enhancing programmes to manage pain in black women of all ages with SLE.

Education showed less consistent interaction with self-efficacy on fatigue and pain interference. The most salient was lower pain interference in women with higher education at mean and high levels of symptom selfefficacy. Previous studies have described an association between education and self-efficacy, which in turn can impact self-care and modify how patients function in relation to pain. ${ }^{39}$ Our data also suggest that individuals with lower educational attainment may be more responsive to interventions designed to enhance self-efficacy, which has been previously emphasised. ${ }^{62}$

Our study has some limitations. First, the crosssectional design does not allow to infer causality; longitudinal studies are thought to provide better estimates of change since each subject is his or her own control. Second, we assumed the relationship between outcome and self-efficacy is linear, but if the relationship might be more appropriately modelled as a non-linear relationship then trends estimated longitudinally and cross-sectionally may differ. Third, although we adjusted the models for multiple factors, we cannot rule out residual and unmeasured confounders. Fourth, disease activity was measured with SLAQ a patient-reported tool that may capture noninflammatory symptoms. Consequently, we conducted sensitivity analyses to examine specific models after additional adjustments for prednisone and/or immunosuppressive drugs (as surrogates of disease activity), obtaining similar results. Fifth, the sheer number of analyses may result in accidental significant findings.
Sixth, our findings are best generalised to black women in Southeastern USA and not to other racial groups in other regions or countries. Moreover, as our design did not include non-SLE controls, we could not determine if our findings are unique to SLE.

Our study has several strengths. To our knowledge, this is the first study to examine the relationships of both pain intensity and fatigue with self-efficacy in an understudied SLE population. While most studies in people with chronic conditions focused on general self-efficacy, we addressed two relevant self-efficacy dimensions. Moreover, we explored the combined effect of different levels of self-efficacy with three factors that can potentially modify those relationships. We used baseline data from the WELL study, a large sample of black women with SLE gathered to examine the effectiveness of the CDSMP in this population. A group of these participants were further exposed to the CDSMP programme. Because self-efficacy is the underpinning mechanism to change behaviours in the CDSMP, these findings will help guide our longitudinal analysis.

In summary, our findings underscore an inverse association between two self-efficacy dimensions and both fatigue and pain interference. Depression, a highly prevalent and often underdiagnosed comorbidity in patients with SLE, may reduce the beneficial effect of self-efficacy to control fatigue and pain interference in black women with this condition. Similarly, older women with low selfefficacy, and to a lesser extent those with average selfefficacy, reported disproportionately greater difficulties in dealing with pain. Moreover, education altered the relationships between self-efficacy to manage symptoms and both fatigue and pain interference, particularly demonstrating that college graduates had lower symptoms as self-efficacy increased, compared with less educated women. As reduced pain and fatigue continue to be among the most important treatment goals in patients with SLE, our findings point to the potential benefits of self-efficacy-building interventions to alleviate those symptoms and improve the quality of life of black women with SLE. Our data also suggest that enhancing symptom self-efficacy may be more important than enhancing treatment self-efficacy to control fatigue and pain interference in this population. Longitudinal analyses are warranted to determine whether black women with SLE and depression, as well as those who are older and attained lower education, may respond differently to the CDSMP and other interventions that enhance specific self-efficacy domains.

\footnotetext{
Author affiliations

${ }^{1}$ Department of Medicine, Division of Rheumatology, Emory University School of Medicine, Atlanta, Georgia, USA

2Department of Epidemiology, Rollins School of Public Health, Emory University, Atlanta, Georgia, USA

${ }^{3}$ Department of Biostatistics and Bioinformatics, Rollins School of Public Health, Emory University, Atlanta, Georgia, USA

${ }^{4}$ Clarity Consulting and Communications, Atlanta, Georgia, USA
} 
Acknowledgements The authors would like thank the WELL and GOAL research coordinators for their efforts, as well as Grady Memorial Hospital and the patients with lupus who participate in our research.

Contributors All authors were involved in drafting the article and/or critically revising it for important intellectual content, and all authors approved the final version to be published. $\mathrm{CD}, \mathrm{KE}, \mathrm{SSL}$ and TB contributed to the study conception and design. CD-T and GB contributed to the acquisition of data. All authors contributed to the analysis and interpretation of data. $\mathrm{CD}$ is the author responsible for the overall content as the guarantor.

Funding The Women Empowered to Live with Lupus (WELL) study is supported by the National Institute on Minority Health and Health Disparities (NIMHD R01MD010455) and the GOAL cohort by the Centers for Disease Control and Prevention (CDC U01DP005119 and U01DP006488). The findings and conclusions in this report are those of the authors and do not necessarily represent the official position of the NIMHD nor the CDC

Competing interests None declared.

Patient consent for publication Not required.

Ethics approval This study involves human participants and was approved by the Emory Institutional Review Board (number 00003656). The Emory Institutional Review Board and Grady Research Oversight Committee approved the GOAL and WELL study protocols. Participants gave informed consent to participate in the study before taking part.

Provenance and peer review Not commissioned; externally peer reviewed. Data availability statement Data are available upon reasonable request. All data relevant to the study are included in the article or uploaded as supplementary information. The WELL study is an ongoing behavioural trial registered on 7 December 2016. We will share individual de-identified data (and metadata and trial documents) via a data use agreement after the study is completed and primary papers are published. Individual de-identified data provided in this report are available upon a data use agreement.

Supplemental material This content has been supplied by the author(s). It has not been vetted by BMJ Publishing Group Limited (BMJ) and may not have been peer-reviewed. Any opinions or recommendations discussed are solely those of the author(s) and are not endorsed by BMJ. BMJ disclaims all liability and responsibility arising from any reliance placed on the content. Where the content includes any translated material, BMJ does not warrant the accuracy and reliability of the translations (including but not limited to local regulations, clinical guidelines, terminology, drug names and drug dosages), and is not responsible for any error and/or omissions arising from translation and adaptation or otherwise.

Open access This is an open access article distributed in accordance with the Creative Commons Attribution Non Commercial (CC BY-NC 4.0) license, which permits others to distribute, remix, adapt, build upon this work non-commercially, and license their derivative works on different terms, provided the original work is properly cited, appropriate credit is given, any changes made indicated, and the use is non-commercial. See: http://creativecommons.org/licenses/by-nc/4.0/.

\section{ORCID iDs}

Cristina Drenkard http://orcid.org/0000-0002-6832-7291

S Sam Lim http://orcid.org/0000-0003-2361-0787

\section{REFERENCES}

1 Danoff-Burg S, Friedberg F. Unmet needs of patients with systemic lupus erythematosus. Behav Med 2009;35:5-13.

2 lannuccelli C, Spinelli FR, Guzzo MP, et al. Fatigue and widespread pain in systemic lupus erythematosus and Sjögren's syndrome: symptoms of the inflammatory disease or associated fibromyalgia? Clin Exp Rheumatol 2012;30:117-21.

3 Schmeding A, Schneider M, Fatigue SM. Fatigue, health-related quality of life and other patient-reported outcomes in systemic lupus erythematosus. Best Pract Res Clin Rheumatol 2013;27:363-75.

4 Wang B, Gladman DD, Urowitz MB. Fatigue in lupus is not correlated with disease activity. J Rheumatol 1998;25:892-5.

5 Baker K, Pope J. Employment and work disability in systemic lupus erythematosus: a systematic review. Rheumatology 2009;48:281-4.

6 Birt JA, Hadi MA, Sargalo N, et al. Patient experiences, satisfaction, and expectations with current systemic lupus erythematosus treatment: results of the SLE-UPDATE survey. Rheumatol Ther 2021;8:1189-1205.
7 Pettersson S, Lövgren M, Eriksson LE, et al. An exploration of patient-reported symptoms in systemic lupus erythematosus and the relationship to health-related quality of life. Scand $J$ Rheumatol 2012:41:383-90.

8 Jones JT, Cunningham N, Kashikar-Zuck S, et al. Pain, fatigue, and psychological impact on health-related quality of life in childhoodonset lupus. Arthritis Care Res 2016;68:73-80.

9 Waldheim E, Ajeganova S, Bergman S, et al. Variation in pain related to systemic lupus erythematosus (SLE): a 7-year follow-up study. Clin Rheumatol 2018;37:1825-34.

10 Nichilatti LP, Fernandes JM, Marques CP. Physiopathology of pain in systemic erythematosus lupus. Lupus 2020;29:721-6.

11 Zielinski MR, Systrom DM, Rose NR. Fatigue, sleep, and autoimmune and related disorders. Front Immunol 2019;10:10.

12 laboni A, Ibanez D, Gladman DD, et al. Fatigue in systemic lupus erythematosus: contributions of disordered sleep, sleepiness, and depression. J Rheumatol 2006;33:2453-7.

13 Arnaud L, Gavand PE, Voll R, et al. Predictors of fatigue and severe fatigue in a large international cohort of patients with systemic lupus erythematosus and a systematic review of the literature. Rheumatology 2019;58:987-96.

14 Azizoddin DR, Gandhi N, Weinberg S, et al. Fatigue in systemic lupus: the role of disease activity and its correlates. Lupus 2019;28:163-73.

15 Moldovan I, Cooray D, Carr F, et al. Pain and depression predict selfreported fatigue/energy in lupus. Lupus 2013;22:684-9.

16 Torrente-Segarra V, Carbonell-Abelló J, Castro-Oreiro S, et al. Association between fibromyalgia and psychiatric disorders in systemic lupus erythematosus. Clin Exp Rheumatol 2010;28:S22-6.

17 Pitcher MH, Von Korff M, Bushnell MC, et al. Prevalence and profile of high-impact chronic pain in the United States. J Pain 2019;20:146-60.

18 Edwards CL, Fillingim RB, Keefe F. Race, ethnicity and pain. Pain 2001;94:133-7.

19 Figueiredo-Braga M, Cornaby C, Cortez A, et al. Depression and anxiety in systemic lupus erythematosus: the crosstalk between immunological, clinical, and psychosocial factors. Medicine 2018;97:e11376.

20 Torrente-Segarra V, Salman-Monte TC, Rúa-Figueroa Íñigo, et al. Fibromyalgia prevalence and related factors in a large registry of patients with systemic lupus erythematosus. Clin Exp Rheumatol 2016;34:S40-7.

21 Falasinnu T, Drenkard C, Bao G, et al. The problem of pain in systemic lupus erythematosus: an Explication of the role of biopsychosocial mechanisms. J Rheumatol 2021;48:1279-89.

22 Drenkard C, Bao G, Dennis G, et al. Burden of systemic lupus erythematosus on employment and work productivity: data from a large cohort in the southeastern United States. Arthritis Care Res 2014;66:878-87.

23 Bandura A. Self-Efficacy: toward a unifying theory of behavioral change. Psychol Rev 1977;84:191-215.

24 Jackson T, Wang Y, Wang Y, et al. Self-Efficacy and chronic pain outcomes: a meta-analytic review. J Pain 2014;15:800-14.

25 Brady TJ, Murphy L, O'Colmain BJ, et al. A meta-analysis of health status, health behaviors, and health care utilization outcomes of the chronic disease self-management program. Prev Chronic Dis 2013;10:E07.

26 Franek J. Self-Management support interventions for persons with chronic disease: an evidence-based analysis. Ont Health Technol Assess Ser 2013;13:1-60.

27 Somers TJ, Kurakula PC, Criscione-Schreiber L, et al. Self-Efficacy and pain catastrophizing in systemic lupus erythematosus: relationship to pain, stiffness, fatigue, and psychological distress. Arthritis Care Res 2012;64:1334-40.

28 Tahmassian K, Jalali Moghadam N. Relationship between selfefficacy and symptoms of anxiety, depression, worry and social avoidance in a normal sample of students. Iran J Psychiatry Behav Sci 2011;5:91-8.

29 Jaycox LH, Stein BD, Paddock S, et al. Impact of teen depression on academic, social, and physical functioning. Pediatrics 2009;124:e596-605.

30 Hammen C. Stress generation in depression: reflections on origins, research, and future directions. J Clin Psychol 2006;62:1065-82.

31 Blazer DG. Self-Efficacy and depression in late life: a primary prevention proposal. Aging Ment Health 2002;6:315-24.

32 Jerant A, Kravitz R, Moore-Hill M, et al. Depressive symptoms moderated the effect of chronic illness self-management training on self-efficacy. Med Care 2008;46:523-31.

33 Harrison M, Reeves D, Harkness E, et al. A secondary analysis of the moderating effects of depression and multimorbidity on the 
effectiveness of a chronic disease self-management programme. Patient Educ Couns 2012;87:67-73.

$34 \mathrm{Kim} \mathrm{G}$, Shim R, Ford KL, et al. The relation between diabetes selfefficacy and psychological distress among older adults: do racial and ethnic differences exist? J Aging Health 2015;27:320-33.

35 Reeves D, Kennedy A, Fullwood C, et al. Predicting who will benefit from an expert patients programme self-management course. $\mathrm{Br} \mathrm{J}$ Gen Pract 2008;58:198-203.

36 Ritter PL, Ory MG, Laurent DD, et al. Effects of chronic disease self-management programs for participants with higher depression scores: secondary analyses of an on-line and a small-group program. Transl Behav Med 2014;4:261024064:398-406.

37 Ory MG, Smith ML, Ahn S. National study of chronic disease selfmanagement: age comparison of outcome findings. Health Educ Behav 2014:41:498182816:34-42.

38 Turnbull S, Cabral C, Hay A, et al. Health equity in the effectiveness of web-based health interventions for the self-care of people with chronic health conditions: systematic review. J Med Internet Res 2020;22:e17849-e.

39 Leganger A, Kraft P. Control constructs: do they mediate the relation between educational attainment and health behaviour? J Health Psychol 2003;8:361-72.

40 Drenkard C, Easley K, Bao G, et al. Overcoming barriers to recruitment and retention of African-American women with SLE in behavioural interventions: lessons learnt from the well study. Lupus Sci Med 2020;7.

41 Lim SS, Drenkard C. Understanding lupus disparities through a social determinants of health framework: the Georgians organized against lupus research cohort. Rheum Dis Clin North Am 2020;46:613-21.

42 Khanna D, Krishnan E, Dewitt EM, et al. The future of measuring patient-reported outcomes in rheumatology: patient-reported outcomes measurement information system (PROMIS). Arthritis Care Res 2011;63 Suppl 11:S486-90.

43 Katz P, Yazdany J, Trupin L, et al. Psychometric evaluation of the National Institutes of health patient-reported outcomes measurement information system in a Multiracial, multiethnic systemic lupus erythematosus cohort. Arthritis Care Res 2019;71:1630-9.

44 (PROMIS) P-ROMIS. Promis depression scoring manual. National Institutes of Health: Northwestern University, 2015.

45 Ameringer S, Elswick RK, Menzies V, et al. Psychometric evaluation of the patient-reported outcomes measurement information system Fatigue-Short form across diverse populations. Nurs Res 2016;65:279-89.

46 Bingham lii CO, Gutierrez AK, Butanis A, et al. Promis fatigue short forms are reliable and valid in adults with rheumatoid arthritis. $J$ Patient Rep Outcomes 2019;3:14.

47 Katz P, Yazdany J, Trupin L, et al. Psychometric evaluation of the NIH Patient-Reported Outcomes Measurement Information
System (PROMIS((R))) in a multi-racial, multi-ethnic systemic lupus erythematosus (SLE) cohort. Arthritis Care Res (Hoboken) 2018.

48 Gruber-Baldini AL, Velozo C, Romero S, et al. Validation of the PROMIS ${ }^{\circledR}$ measures of self-efficacy for managing chronic conditions. Qual Life Res 2017;26:1915-24.

49 Kuhl EA, Kupfer DJ, Regier DA. Patient-Centered revisions to the DSM-5. Virtual Mentor 2011;13:873-9.

50 Narrow WE, Kuhl EA. Dimensional approaches to psychiatric diagnosis in DSM-5. J Ment Health Policy Econ 2011;14:197-200.

51 Pilkonis PA, Yu L, Dodds NE, et al. Validation of the depression item bank from the patient-reported outcomes measurement information system (PROMIS) in a three-month observational study. J Psychiatr Res 2014;56:112-9.

52 Choi SW, Schalet B, Cook KF, et al. Establishing a common metric for depressive symptoms: linking the BDI-II, CES-D, and PHQ-9 to PROMIS depression. Psychol Assess 2014;26:513.

53 Gibbons LE, Feldman BJ, Crane HM, et al. Migrating from a legacy fixed-format measure to cat administration: calibrating the PHQ-9 to the PROMIS depression measures. Qual Life Res 2011;20:1349-57.

54 Karlson EW, Daltroy LH, Rivest C, et al. Validation of a systemic lupus activity questionnaire (SLAQ) for population studies. Lupus 2003;12:280-6.

55 Drenkard C, Yazdany J, Trupin L, et al. Validity of a self-administered version of the brief index of lupus damage in a predominantly African American systemic lupus erythematosus cohort. Arthritis Care Res 2014;66:888-96.

56 Ritter PL, Lee J, Lorig K. Moderators of chronic disease selfmanagement programs: who benefits? Chronic IIIn 2011;7:162-72.

57 Sun K, Eudy AM, Criscione-Schreiber LG, et al. Racial differences in patient-provider communication, patient self-efficacy, and their associations with systemic lupus erythematosus-related damage: a cross-sectional survey. J Rheumatol 2021;48:1022-8.

58 Farivar SS, Liu H, Hays RD. Half standard deviation estimate of the minimally important difference in $\mathrm{HRQOL}$ scores? Expert Rev Pharmacoecon Outcomes Res 2004;4:515-23.

59 Sclar DA, Robison LM, Schmidt JM, et al. Diagnosis of depression and use of antidepressant pharmacotherapy among adults in the United States: does a disparity persist by ethnicity/race? Clin Drug Investig 2012;32:139-44.

60 Portenoy RK, Ugarte C, Fuller I, et al. Population-Based survey of pain in the United States: differences among white, African American, and Hispanic subjects. J Pain 2004;5:317-28.

61 Rahim-Williams B, Riley JL, Williams AKK, et al. A quantitative review of ethnic group differences in experimental pain response: do biology, psychology, and culture matter? Pain Med 2012;13:522-40.

62 Pandey DK, Dasgupta R, Levy J, et al. Enhancing epilepsy selfmanagement and quality of life for adults with epilepsy with varying social and educational backgrounds using pause to learn your epilepsy. Epilepsy Behav 2020;111:107228. 